\title{
INTERthesis
}

\section{PERMACULTURA COMO UM ESTILO DE VIDA SUSTENTÁVEL: O OLHAR DA PSICOLOGIA AMBIENTAL}

\section{Resumo:}

Raquel Farias Diniz ${ }^{1}$

Em vista da crise ecológica que se evidência ao longo das últimas décadas, faz-se necessário o entendimento de que vários problemas ambientais têm como base o comportamento humano. Nesse sentido, a ciência psicológica busca contribuir para a construção de conhecimento sobre os processos cognitivos, emocionais e motivacionais que predispõem comportamentos em prol da conservação do meio ambiente e para a formação de sujeitos ecológicos. Sob o referencial da sustentabilidade, a Psicologia Ambiental tem se dedicado a compreender os estilos de vida sustentáveis (EVS), suas predisposições psicológicas e suas práticas efetivas. No presente ensaio argumenta-se que a Permacultura, como ética e modo de vida contra-hegemônico, se configura como um EVS. Ao discutir essa relação, considera-se seu potencial para problematizar os modos de vida contemporâneos e fomentar novos caminhos para a transformação das relações pessoa-ambiente.

Palavras-chave: Psicologia Ambiental. Estilo de Vida. Sustentabilidade. Permacultura. Cuidado Ambiental.

\section{INTRODUÇÃO}

O ser humano é produto das demandas evolucionárias do seu tempo, o que o leva a se relacionar com o ambiente de diferentes formas ao longo da história da civilização ocidental. Nas etapas iniciais da história, o homem natural era dependente e extremamente ligado à natureza, em sua luta pela existência, momento em que não exercia impacto sobre o equilíbrio ecológico. Já na era medieval, a equação humano-ambiente adquire novos valores, a natureza deixa de ser o único espelho no qual os seres humanos têm o seu reflexo e o mundo se torna mais social e conceptual. No renascimento, o homem do cristianismo dá lugar ao homem racional, idealizado pelas grandes descobertas científicas do século dezoito e pelo avanço do modo de vida industrial no século dezenove.

\footnotetext{
1 Doutora em Psicologia pela Universidade Federal do Rio Grande do Norte. Participante do Grupo de Estudos Inter-Ações Pessoa-Ambiente, professora nas áreas de História da Psicologia, Psicologia Social e Comunitária, Metodologia Científica e em ensino e pesquisa na área de Psicologia Ambiental com os temas: comportamento pró-ecológico e estilos de vida sustentáveis, histórias de vida e temporalidade na Universidade Federal do Rio Grande do Norte, Natal, RN, Brasil E-mail: raquelfdiniz@gmail.com
} 
Apesar dessas variações no autoconceito humano em diferentes momentos da história ocidental emerge, no fim do século XIX, o conceito de identidade como psicologicamente genérico. Da noção individualizante do homem psicológico, depreende-se a ideia de singularidade, que se distancia dos valores de transcendência e espiritualidade, tão característicos em momentos anteriores. É a partir dessa noção que se começa a pensar em ambiente e comportamento levando ao homem ambiental, ou mais, pessoa ambiental consciente de seu ambiente e da interdependência que os une. É esta "virada ontológica" que remove o indivíduo do isolamento físico em que ele vinha (e em várias áreas continua) sendo estudado e que serve aos propósitos do campo de estudos das relações pessoa-ambiente (ITTELSON et al., 1974).

Tal mudança na visão de ser humano possibilita reflexões acerca do seu papel ativo na perturbação do equilíbrio ecológico e como uma das causas que acentuam os sinais da crise ambiental. Considera-se, portanto, que a autocompreensão constitui uma alternativa em face dos problemas ambientais que, fundamentalmente, são problemas humanos (TUAN, 1980). É necessário ter em conta que os problemas ambientais não são apenas problemas de ordem técnica que requerem soluções da física, da química ou da engenharia. As ciências sociais adquirem um papel crucial nesse contexto, levando em consideração a ação humana como intrinsecamente ligada à perturbação do equilíbrio ambiental (OSKAMP, 2000; KURZ 2002).

Nesse sentido, a Psicologia vem sendo convocada a cumprir seu papel no entendimento dos processos cognitivos, emocionais e motivacionais que favorecem comportamentos em prol do meio ambiente. O estudo das transações entre as pessoas e 0 ambiente busca promover uma harmonia entre ambos $e$, consequentemente, o bem-estar humano e a sustentabilidade ambiental (WIESENFELD, 2005). A Psicologia Ambiental (PA) se insere no campo dos estudos pessoa-ambiente e lança mão de seu aparato teórico-metodológico e do seu referencial da interdependência para tratar da bidirecionalidade das relações humano-ambientais.

Especificamente, no que se refere à sustentabilidade, esta disciplina busca contribuir para o entendimento, e consequente esforço por conter o descompasso entre o estilo de vida comum à boa parte dos 7 bilhões de habitantes do planeta e a 
manutenção dos recursos naturais. A promoção de comportamentos orientados pelo ideal de satisfação das necessidades das sociedades atuais sem comprometer a renovação desses recursos, tal como proposto no relatório Nosso Futuro Comum (1987), torna-se um desafio posto para nossa geração em prol das gerações futuras.

Kazdin (2009) aponta a PA como uma disciplina central e passível de formar parcerias com diversos campos do saber de forma a contribuir para esse cenário. $O$ autor refere-se aos problemas ambientais como grandes desafios e afirma que os mesmos exigem novas formas de pensar e elaborar estratégias de resolução. Afirma, ainda, que a psicologia está numa clara expansão em direção a questões críticas e de impacto na sociedade, e aponta a sustentabilidade como uma nova etapa de direcionamento da atenção e recursos humanos.

Dentre as temáticas exploradas no âmbito do estudo das relações pessoaambiente em sua aproximação com a sustentabilidade, a noção de estilos de vida sustentáveis apresenta-se com fundamental importância. Tal noção sinaliza uma via de compreensão basilar para a promoção de comportamentos que resultem na preservação dos recursos naturais, pois contempla tanto a dimensão efetiva das práticas de cuidado ambiental como dimensões de natureza psicológica que predispõem tais práticas.

\section{OS ESTILOS DE VIDA SUSTENTÁVEIS}

Em vista da relevância do tema no campo das relações pessoa-ambiente, a pró-ambientalidade, ou seja, as posturas em favor do meio ambiente têm sido foco de um número de investigações cada vez mais crescente. Os estudos neste contexto comportam diferentes nomenclaturas (comportamento pró-ambiental, comportamento de conservação, atitudes ambientais, conduta sustentável, cuidado ambiental, entre outros), mas com objetivo comum de compreender os comportamentos de base pró-ecológica e os fatores envolvidos em sua promoção.

Contudo, considerando a complexidade que a sustentabilidade traz para a definição da pró-ambientalidade, Corral-Verdugo e Pinheiro (2004, p.10) definiram os estilos de vida sustentáveis como "o conjunto de ações efetivas, deliberadas e antecipadas que resultam na preservação dos recursos naturais, incluindo a integridade das espécies animais e vegetais, assim como o bem-estar individual e 
social das gerações atuais e futuras". Trata-se, portanto, de um conceito multidimensional que extrapola o nível das intenções e do discurso, contemplando práticas efetivas de cuidado ambiental que levam em conta uma perspectiva temporal de futuro.

Tal como proposto, o estilo de vida sustentável caracteriza uma conceituação ambiciosa e de difícil abordagem empírica, por englobar fundamentalmente a dimensão comportamental aliada a preceitos inerentes à noção de sustentabilidade, como a perspectiva temporal de futuro. Corral-Verdugo (2010) reuniu tais dimensões psicológicas em três eixos: predisposições, repercussões psicológicas, e comportamentos.

O primeiro eixo, relativo às predisposições psicológicas, reúne um conjunto de determinantes que antecedem o comportamento. Nesse eixo são contempladas as visões de mundo, concebidas como sistemas de crenças que orientam a ação pró ou antiecológica; a deliberação, vontade e intenção de atuar; o apreço pela diversidade, marcado pela tendência em preferir a complexidade e as variações no meio biofísico e sociocultural; as emoções, relativas aos afetos positivos em relação ao meio ambiente; a efetividade, que comporta habilidades e competências para atuar; e a orientação de futuro, ou seja, a antecipação de consequências das ações.

No eixo relativo aos benefícios psicológicos dos estilos de vida sustentáveis, Corral-Verdugo $(2010 ; 2012)$ trata da aproximação entre psicologia ambiental e psicologia positiva ao afirmar que a felicidade e o bem-estar subjetivo estão entre os objetivos da sustentabilidade. Os poucos estudos realizados nesta interface já apontam que pessoas que cuidam do meio ambiente apresentam altos índices de felicidade e promovem ações que resultam na felicidade de outras pessoas. Outra resultante positiva seria o contato com ambientes naturais que atuam como restauradores, proporcionando melhoria na qualidade de vida e satisfação.

Por fim, o terceiro eixo engloba a dimensão comportamental, que se constitui como algo inerente ao estilo de vida sustentável. O comportamento pró-ecológico compreende "o conjunto de ações deliberadas e efetivas que respondem a requerimentos sociais e individuais e que resultam na proteção do meio" (CorralVerdugo, 2001, p. 40). Esta dimensão engloba a austeridade, relativa ao uso de produtos sem o afã consumista, práticas de cooperação e busca pela equidade na distribuição de recursos e acesso a benefícios. 
Estudos mais recentes vêm destacando novas dimensões psicológicas associadas aos EVS. Muiños et al., (2015) apontaram a frugalidade como uma dessas dimensões, sendo definida como a restrição deliberada do consumo de recursos e bens, assim como seu uso engenhoso, considerando uma perspectiva em longo prazo. Olivos e Aragonés (2011) demonstraram que quanto mais as pessoas se identificam com a natureza e com o meio ambiente, mais elas se comportam de forma pró-ecológica.

Diante do exposto, propõe-se no presente ensaio a aproximação entre as dimensões do estilo de vida sustentável com a proposta da Permacultura, sendo esta, parte de um movimento contemporâneo de questionamento e transformação das relações pessoa-ambiente.

\section{PERMACULTURA E O SER SUSTENTÁVEL}

O surgimento da agricultura data de dez milênios atrás, estando alinhado com o processo de sedentarização, da domesticação de animais e com as primeiras organizações humanas. A divisão do trabalho era feita entre caçadores e coletores, comum também aos povos indígenas e outras culturas tradicionais que, até hoje, em várias partes do planeta, seguem de forma bem sucedida seus projetos de vida. Contudo, como visto num espectro mais amplo, essa história avança até o ponto em que estamos hoje: um contexto de crise humano-ambiental, marcado pela imposição de formas destrutivas de produção agrícola e de relação com a natureza.

A partir da constatação de que, para fazer frente a essa crise, não era suficiente a oposição aos sistemas políticos e industriais que acentuavam a degradação ambiental, no começo dos anos de 1970 os australianos Bill Mollison e David Holmgren desenvolveram a Permacultura: uma síntese de práticas agrícolas tradicionais com ideias inovadoras, unindo o conhecimento milenar às descobertas da ciência moderna (SOARES, 1998). Ainda fora dos dicionários de língua portuguesa, a palavra nasce da contração dos termos permanente e agricultura, assim como da ideia de cultura permanente, sendo definida como,

um sistema de design para a criação de ambientes humanos sustentáveis. (...) O objetivo é a criação de sistemas que sejam ecologicamente corretos e economicamente viáveis; que supram suas próprias necessidades, não explorem ou poluam e que, assim, sejam sustentáveis em longo prazo (MOLLISSON, 1998, p. 13). 
Desta definição se depreende uma série de implicações dentre elas, a associação deste conceito com a noção de sustentabilidade e a positividade da proposta, que não se coloca no nível do discurso - ou de uma visão de futuro -, mas sim como uma prática viável, e necessária, para o presente. Tem explícita a importância da dimensão temporal que, como afirma Pinheiro (2002), trata-se de um aspecto fundamental nas relações pessoa-ambiente, com ênfase na perspectiva de futuro que pressupõe a solidariedade intergeracional, presente na própria definição de sustentabilidade.

Quando a mudança no nosso modo de vida parte do terror e do medo com a previsão de maremotos e catástrofes, a onda passa e o foco das preocupações pode mudar. Uma mudança efetiva, por outro lado, deveria partir do reconhecimento de que os sistemas reais que estão começando a falhar são os solos, florestas, a atmosfera, e os ciclos de nutrientes. E, embora sejamos os responsáveis por isso, até então, não se havia consolidado em nenhum lugar do mundo (a não ser em áreas tribais) um sistema sustentável de agricultura ou manejo de florestas (MOLLISON, 2001).

A Permacultura leva à adoção de uma ética específica, respaldada em três pilares: cuidado com o planeta Terra, que implica cuidar das coisas vivas e não vivas, como solos, espécies, águas, ar, com atividades inofensivas, reabilitantes e de conservação; cuidado com as pessoas, de forma a suprir as necessidades básicas de alimentação, abrigo, educação, trabalho satisfatório e contato humano saudável; e cuidado com a distribuição do excesso de tempo, dinheiro e materiais para atingir estes fins. De acordo com o último pilar, depois de supridas as necessidades básicas e projetados nossos sistemas da melhor forma possível, poderemos auxiliar outros no alcance destes objetivos. A Permacultura mantém ainda uma ética de vida, a qual reconhece o valor intrínseco a todas as formas de vida, e com isso permeia todos os aspectos dos sistemas ambientais, comunitários, sociais e econômicos (MOLLISON, 1998).

As formas de implementar a ética permacultural estão contempladas num planejamento para a sustentabilidade, com base no uso de espécies nativas, cultivadas numa menor área de terra possível (sistema intensivo), valorizando a policultura e focalizando a produção total do sistema, com o cultivo de plantas anuais e perenes. Busca-se também trazer a produção de alimentos de volta às 
cidades e vilarejos e ajudar as pessoas a se tornarem auto-suficientes, assim como promover a responsabilidade comunitária. Visa ainda à utilização de tudo até o máximo e a reciclagem de todos os resíduos (MOLLISON, 1998).

Na prática, a tradução do termo design que está em sua definição vai além de desenho. Trata-se de um planejamento consciente, considerando todas as influências e inter-relacionamentos entre os elementos de um sistema vivo. As resultantes desse planejamento, quando feito de forma adequada, devem incluir: estratégias para a utilização da terra sem desperdício ou poluição, sistemas de produção de alimento saudável, restauração de paisagens degradadas e preservação de espécies, integração de todos os organismos vivos em um ambiente de interação e cooperação em ciclos naturais, mínimo de consumo de energia e a captação e armazenamento de água e nutrientes (SOARES, 1998).

Um dos objetivos centrais desse planejamento é a economia de energia, com a minimização do uso de energia fóssil. Considera-se que a energia deve fluir ciclicamente, pois quanto menos energia externa, mais autossuficiente é o sistema. $\mathrm{Na}$ Permacultura, a matéria orgânica e a água da chuva, por exemplo, são consideradas potenciais fontes de energia. A eficiência no uso dos recursos só é possível a partir da observação atenta dos ciclos da natureza e de suas interconexões (HENDERSON, 2012).

O planejamento permacultural respeita as especificidades de cada região onde será implantado. É feito por setores, onde o sítio é o centro do sistema e o espaço circundante é marcado de acordo com as informações coletadas sobre a região: setor de luz solar no inverno e no verão, setor dos ventos, setor de perigo de incêndio, etc. Em seguida, é feito o planejamento por zonas, que visa a uma economia máxima de trabalho e recursos, criando pontos de produção dos recursos que serão ali utilizados. A primeira zona é a casa, planejada ou modificada para a eficiência na produção de alimentos; na zona 2 ficam os elementos que necessitam de cuidado diário como horta, ervas, animais de pequeno porte; na zona 3 ficam os cultivos com fins comerciais, como florestas de alimentos (agroecologia), animais de médio porte; a zona 4 é visitada mais raramente, onde fica a produção de madeiras valiosas, açudes maiores e animais silvestres; por fim, a zona 5 é onde não se interfere, permitindo que exista um desenvolvimento natural e serve de referência 
para os processos que se tenta incluir nas outras zonas (MOLLISON, 1998; SOARES, 1998).

A prática da Permacultura envolve um cenário interdisciplinar composto por diferentes técnicas que fazem a junção de conhecimentos tradicionais (da prática indígena, camponesa) com estratégias desenvolvidas pela biologia, engenharia florestal, ecologia, geologia, química, entre outras. A agroecologia e os sistemas agroflorestais, por exemplo, desenvolvem sistemas de plantio que se baseiam no funcionamento da floresta, consorciando plantas de diferentes tipos e ciclos, com a associação de plantas nativas a exóticas, resultando no aumento da biodiversidade, da estabilidade e da produção de alimentos. As bioconstruções oferecem uma alternativa para o uso do cimento, como o uso do tijolo de adobe. Recursos de captação de água da chuva e o banheiro seco (com uso de câmaras de compostagem) são tecnologias sustentáveis também usadas nas bioconstruções, assim como as energias alternativas (e.g., solar, eólica, biomassa) (HENDERSON, 2012).

Como afirmam Soares e Oliveira Junior (2010), além de adotar uma racionalidade compatível com a produção familiar, a Permacultura vai ao encontro aos modos de vida típicos do padrão vigente, podendo ser considerado um modo de viver contra-hegemônico; pois estabelece locais de resistência à ordem imposta, modificando e criando novos paradigmas e processos com potencial para transformar diversos contextos de vida.

No Brasil, o fato de todo trabalho relacionado à mão de obra ser desmerecido, representa um desafio ainda maior para difundir uma mudança de cultura, na qual as pessoas produziriam seu próprio alimento. Todavia, a Permacultura é desenvolvida no Brasil há quinze anos, tendo começado com espaços de visitação e hoje já conta com editais de financiamento que a colocam como base para projetos (INTITUTO HUMANISTAS UNISINOS ON-LINE, 2013).

A rede de Permacultura no Brasil é composta atualmente por nove institutos, distribuídos nas regiões centro-oeste (Instituto de Permacultura e Ecovilas do Cerrado-GO e Instituto de Permacultura: Organização, Ecovilas e Meio AmbienteDF), nordeste (Instituto de Permacultura da Bahia-BA, Instituto de Permacultura em Terras Secas-BA Organização de Permacultura e Arte-BA e Instituto de Permacultura Ceará-CE), sudeste (Instituto de Permacultura e Ecovilas da Mata 
Atlântica-SP e Ecovila São Miguel-MG) e sul (Instituto de Permacultura do Rio Grande do Sul-RS). Estes institutos se caracterizam como organizações não governamentais, sem fins lucrativos, nos quais são conduzidos projetos socioambientais e são ofertados cursos, oficinas, vivências, visitação e consultorias. Encontram-se também comunidades/sítios/casas cadastradas na rede, distribuídas nestas regiões desenvolvendo experiências permaculturais e oferecendo cursos de formação e oportunidades de visitação e trabalho voluntário.

\section{UM ESTILO DE VIDA CONTRA-HEGEMÔNICO}

Diante do exposto, observa-se que a Permacultura se aproxima da noção de estilo de vida sustentável, em outras palavras, ela traduz para o campo do real o fenômeno psicológico enfocado pela PA. A multidimensionalidade do EVS pode ser encontrada na ética e na prática permacultural, que valorizam tanto o bem-estar humano quanto o ambiental, numa perspectiva essencialmente ecossistêmica e de valorização e zelo por todas as formas de vida.

Do ponto de vista da ética permacultural, os três pilares que se referem ao cuidado com as pessoas, com o meio ambiente e o compartilhamento de excedentes, contemplam as dimensões que predispõem um estilo de vida sustentável. Parte de um sistema de crenças ecocêntricas, ou seja, de reconhecimento do valor intrínseco, da interdependência e da diversidade de todos os elementos que compõem os ecossistemas. Tais pilares éticos inferem, também, a deliberação das práticas nesse contexto, sendo conscientes e voluntárias, assim como o reconhecimento da importância de considerar as consequências futuras das ações praticadas no presente, que contempla a temporalidade presente na definição da sustentabilidade.

Ao se referir ao cuidado com os diversos elementos que constituem os ecossistemas, a ética permacultural tem implícito, também, a dimensão afetiva, contemplando as repercussões positivas das práticas. Há a valorização do bemestar, a busca pela satisfação no contato direto com ambientes naturais, e a promoção de relações humanas saudáveis.

Em relação às práticas, ao modo de organização e interação com o ambiente, as práticas permaculturais constituem a dimensão comportamental dos estilos de 
vida sustentáveis. São marcadas pela austeridade e pela frugalidade, visto que se definem pela redução e restrição do consumo e pelo uso engenhoso dos recursos disponíveis, constituindo práticas de subsistência e auto-sustentáveis. São marcadas, também, pelo caráter cooperativo e de ajuda mútua, com a ênfase na equidade e divisão justa dos recursos, do tempo e das atividades.

Nesse sentido, argumenta-se que a Permacultura, como um estilo de vida, atinge os ideais da sustentabilidade. E, dentro de marcos éticos e políticos, um estilo de vida orientado para a sustentabilidade se configura como uma oposição voluntária e deliberada aos modos de vida hegemônicos na cultura ocidental. Conclui-se que, embora se aproxime de um ideal, e que seja de difícil consecução dentro dessa cultura, seus princípios e sua ética podem orientar a formação de sujeitos ecológicos e fornecer as bases para transformações cotidianas que possam levar ao questionamento dos padrões de consumo impostos e possam ter impacto nos modos de vidas contemporâneos. 


\title{
PERMACULTURE AS A SUSTAINABLE LIFESTYLE: THE VISION OF ENVIRONMENTAL PSYCHOLOGY
}

\begin{abstract}
:
Due to the ecological crisis evident over the past decades, it is necessary to understand that various environmental problems are based on human behavior. In this sense, the psychological science seeks to contribute to the construction of cognitive, emotional and motivational knowledge processes that predispose behaviors in favor of the environmental conservation and to the development of ecological individuals. Under the sustainability framework, environmental psychology has been devoted to understanding sustainable lifestyles (SLS), its psychological predispositions and its effective practices. In this essay it is argued that the Permaculture, such as ethics and counter-hegemonic way of life, is configured as an SLS. In discussing this relationship, it is considered its potential to question contemporary ways of life and foster new pathways to the transformation of humanenvironment relations.
\end{abstract}

Keywords: Environmental Psychology. Lifestyle. Sustainability. Permaculture. Environmental Care.

\section{PERMACULTURA COMO UN ESTILO DE VIDA SUSTENTABLE: LA MIRADA DE LA PSICOLOGÍA AMBIENTAL}

\section{Resumen:}

Con vista a la crisis ecológica que es evidente en las últimas décadas, es necesario el entendimiento de que varios problemas ambientales se basan en el comportamiento humano. En este sentido, la ciencia psicológica busca contribuir a la construcción del conocimiento sobre los procesos cognitivos, emocionales y motivacionales que predisponen a una conducta favorable a la conservación del medio ambiente y para la formación de sujetos ecológicos. En el marco de la sustentabilidad, la Psicología Ambiental se ha dedicado a la comprensión de los estilos de vida sustentables (EVS), sus predisposiciones psicológicas y sus prácticas efectivas. En este ensayo se argumenta que la Permacultura, como ética y forma de vida contra-hegemónica, se configura como un EVS. Al hablar de esta relación, se considera su potencial para cuestionar formas contemporáneas de vida y fomentar nuevas vías para la transformación de las relaciones humano-ambiente.

Palabras clave: Psicología ambiental. Estilo de vida. Sustentabilidad. Permacultura. Cuidado del Medio Ambiente. 


\section{REFERÊNCIAS}

CORRAL-VERDUGO, V. Comportamiento proambiental. Tenerife: Resma, 2001.

CORRAL-VERDUGO, V. Psicologia de la Sustentabilidad: un análisis de lo que nos hace pro-ecológicos y pro-sociales. Cidade do México: Trillas, 2010.

CORRAL-VERDUGO, V. Sustentabilidad y Psicología Positiva: una visión optimista de las conductas proambientales y prosociales. Hermosillo: El Manual Moderno, 2012.

CORRAL-VERDUGO, V; PINHEIRO, J. Aproximaciones al estudio de la conducta sustentable. Medio Ambiente y Comportamiento Humano, v. 1, n. 5, p.1-26, 2004.

COMISSÃO MUNDIAL SOBRE MEIO AMBIENTE E DESENVOLVIMENTO. Nosso futuro comum ( $2^{\mathrm{a}}$ ed.). Rio de Janeiro: Editora da Fundação Getúlio Vargas, 1991.

HENDERSON, D. Permacultura: as técnicas, o espaço, a natureza e o homem. 130 f. Monografia (Especialização) - Curso de Antropologia, Universidade de Brasília, Brasília, 2012.

ITTELSON, W et al. An introduction to Environmental Psychology. Nova York: Holt, Rinehart \& Winston, 1974.

KAZDIN, A. Psychological science's contributions to a sustainable environment: extending our reach to a grand challenge of society. American Psychologist, n. 64, p.339-356, 2009.

KURZ, T. The psychology of environmentally sustainable behavior: fitting together pieces of the puzzle. Analyses Of Social Issues And Public Policy, v. 1, n. 2 , p.257-278, 2002.

MOLLISSON, B. Introdução à Permacultura. Brasília: Ministério do Meio Ambiente, 1998.

MOLLISSON, B. Introdução à Permacultura: panfleto I da Serie Curso de Design em Permacultura. Wilton: Yankee Permaculture, 2001. 
MUIÑOS, $G$ et al. Frugality and psychological wellbeing. The role of voluntary restriction and the resourceful use of resources. Psychology, v. 2, n. 6, p.169-190, 2015.

OLIVOS, P; ARAGONÉS, J. Psychometric properties of the Environmental Identity Scale (EID). Psychology, Madri, v. 1, n. 2, p.65-74, 2011.

OSKAMP, S. Psychological contributions to achieving an ecologically sustainable future for humanity. Journal of Social Issues, n. 56, p.373-390, 2000.

PINHEIRO, J. Apego ao futuro: escala temporal e sustentabilidade em psicologia ambiental. In: CORRAL-VERDUGO, V. Conductas protectoras del ambiente. Teoría, investigación y estrategias de intervención. Hermosillo: Conacyt \& Unison, 2002. Cap. 2. p. 29-48.

INSTITUTO HUMANITAS UNISINOS ON-LINE, Permacultura: por uma outra visão de mundo: entrevista especial com João Rockett. São Leopoldo, Instituto Humanistas Unisinos, 06 jan. 2013. Entrevista a João Rockett. Disponível em: < http://www.ihu.unisinos.br/entrevistas/516749-permacultura-por-outra-visao-demundo-entrevista-especial-com-joao-rockett > Acesso em: 06 jan. 2013

SOARES, A. Conceitos básicos sobre permacultura. Brasília: Ministério do Meio Ambiente, 1998.

SOARES, L L; OLIVEIRA JUNIOR, G. Permacultura: de uma contra-hegemonia para uma nova realidade. In: ENCONTRO DA REDE DE ESTUDOS RURAIS, 4. 2010, Curitiba. Curitiba: Universidade Federal do Paraná, 2010. p. 1 - 2.

TUAN, Y F. Topofilia. São Paulo: Difel, 1980.

WIESENFELD, E. A psicologia ambiental e as diversas realidades humanas.

Psicologia Usp, v. 1, n. 16, p.53-69, 2005.

\section{Artigo}

Recebido em 30 de Agosto de 2015

Aceito em 25 de Março de 2016 